\title{
Auditory effects of recreational and occupational noise exposure among dental students: a cross-sectional study
}

\author{
Eduardo Fuentes-López ${ }^{1}$ \\ https://orcid.org/0000-0002-0141-0226 \\ Francisco García-Huidobro Nuñez ${ }^{2}$ \\ https://orcid.org/0000-0002-5607-0740 \\ Pamela Acuña Caro 1 \\ https://orcid.org/0000-0001-5151-0957 \\ Nicolás Castro Becerra ${ }^{1}$ \\ https://orcid.org/0000-0001-9892-0435 \\ Gabriela Jalil García ${ }^{1}$ \\ https://orcid.org/0000-0001-8221-4659 \\ Nivia Molina Marín 1 \\ https://orcid.org/0000-0002-2032-581X \\ Lissette Navea Stuardo ${ }^{1}$ \\ https://orcid.org/0000-0002-8042-4422 \\ Eduardo Magallón ${ }^{3}$ \\ https://orcid.org/0000-0001-7952-5413 \\ Pedro Badía Venti ${ }^{2}$ \\ https://orcid.org/0000-0003-3960-0807
}

Pontificia Universidad Católica de Chile, Facultad de Medicina, Departamento Ciencias de la Salud, Carrera de Fonoaudiología, Santiago, Chile. Pontificia Universidad Católica de Chile, Facultad de Medicina, Departamento de Otorrinolaringología, Santiago, Chile.

${ }^{3}$ Pontificia Universidad Católica de Chile, Facultad de Medicina, Escuela de Odontología, Chile.

Conflict of interests: Nonexistent

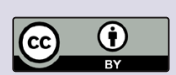

Received on: October 1, 2019

Accepted on: September 13, 2020

Corresponding address:

Eduardo Fuentes-López

Carrera de Fonoaudiología, Departamento Ciencias de la Salud, Facultad de Medicina

Pontificia Universidad Católica de Chile Avenida Vicuña Mackenna 4860, Macul ZIP Code: 7820436 - Santiago, Chile

E-mail: eduardo.fuentes@uc.cl

\section{ABSTRACT}

Purpose: to determine the auditory effects of noise exposure from recreational and occupational sources among dentistry students.

Methods: forty-two dentistry students, routinely exposed to occupational noise, and 72 students from other health science schools were recruited (control group). Audiometric testing, otoacoustic emissions and questionnaires to assess recreational and occupational noise were applied to the sample. The presence of a notch was determined for each participant audiometry's test based on the criteria proposed by Coles et al. Differences in notch prevalence were analyzed by applying univariate regression models as well as a multivariate model adjusted by covariates.

Results: non-significant differences in auditory thresholds between groups were found. The controls exhibited a significantly higher prevalence of a notch at $4 \mathrm{kHz}$ than the group exposed to noise. However, the differences were not statistically significant in the multivariate model adjusted by recreational noise exposure.

Conclusions: the occupational noise exposure was not significantly associated to auditory system dysfunction. In addition, the differences in notch prevalence could be related to recreational noise exposure.

Keywords: Auditory System Dysfunction; Dentistry Students; Noise-induced Hearing Loss; Students 


\section{INTRODUCTION}

Noise-induced hearing loss (NIHL) is a common cause of hearing damage among the population, being estimated that more than 500 million people worldwide are at risk of suffering from it ${ }^{1}$. Among adults, hearing loss affects significantly the quality of life and social and work-place wellbeing ${ }^{2}$. When there are permanently high noise levels in the workplace, hearing loss is called Occupational Noise-induced Hearing Loss $(\mathrm{ONHL})^{3}$. ONHL is characterized by a decrease in high frequencies 3 , 4, and $6 \mathrm{kHz}^{4}$.

Hearing damage may occur as the result of constant exposure to noise above $85 \mathrm{~dB}^{1,5}$. Recent studies indicate that the noise in dental clinics and undergraduate clinical practice setting may be higher than $85 \mathrm{~dB}^{6,7}$. In this setting, the noise caused by dental instruments is amplified by using several pieces of equipment at the same time ${ }^{8}$. Also, working spaces are shared, and there are no soundproof or sound-buffer.

When comparing the hearing thresholds of first-year dentistry students with dentists working for more than five years, a significant decrease was seen at $4 \mathrm{kHz}^{9}$. Also, changes have been observed in otoacoustic emissions at 4 and $6 \mathrm{kHz}$ in the left ear and $6 \mathrm{kHz}$ in the right ear when comparing measurements before and after students' working day ${ }^{10}$.

Nevertheless, in some of the reports, the group exposed to dental noise showed no differences with control individuals ${ }^{11}$. The lower levels of noise produced by dental drilling equipment nowadays ${ }^{11}$, the variability of the subjects studied, and how the presence of noiseinduced hearing loss was determined could partly explain the discrepancy among studies. Also, when not using a clear definition of Noise-induced hearing loss such as the one proposed by Coles et al. ${ }^{12}$, in which only $10 \mathrm{~dB}$ deviations are considered pathological, no signs of the early onset of hearing variations were detected.

In addition, dentistry students, as a large number of young people, are exposed to recreational noise. Going to concerts or listening to music on portable devices at a high intensity contributes to increase in hearing loss in young people ${ }^{13}$, with a high level of exposure among university students ${ }^{14}$. To best of our knowledge, there are currently no studies that determine the effect of exposure to dental noise in university students with an additional higher level of exposure to recreational noise.

Therefore, this study aimed to determine the auditory effects of noise exposure from recreational and occupational sources among dentistry students. It is crucial to determine when hearing damage is present in young students exposed to occupational dental noise. If hearing damage is observed before students begin practicing, the recommendation will be for training institutions to take preventative measures to counteract the adverse effects of exposure to occupational dental noise.

\section{METHODS}

The Scientific Ethics Committee approved the study protocol at the Facultad de Medicina de la Pontificia Universidad Católica de Chile (project ID: 170925001). A cross-sectional study was carried out between March and April 2018. This type of design was chosen since the aim was to compare two groups (whether exposed to occupational noise or not, both with and without hearing damage) and establish relationships between variables using statistical inference. Undergraduate students doing clinical practice with dental instruments were invited to participate. At the same time, the control group was made up of students from other health-related undergraduate programs (Nutrition and Dietetics, Physiotherapy, and Speech-Language Therapy) at the Pontificia Universidad Católica de Chile. They all took part voluntarily after signing an informed consent form.

The sample design was non-probabilistic and included undergraduate students in their second to sixth years. It is necessary to mention that dentistry students are exposed to dental noise from the second year onwards. It was confirmed that none of the dentistry students used ear protection when carrying out activities involving exposure to dental noise. The above mentioned actions aimed to control the misclassification bias among the sample's subjects. Also, students with hearing pathologies unrelated to noise exposure were excluded. To rule out temporary hearing loss, those exposed to recreational noise 24 hours before the exam were excluded. Of a total of 148 students who voluntarily agreed to take part in the study, $15(7 \%)$ were excluded because they had earwax. Another 23 (16\%) were excluded for being exposed to recreational noise 24 hours before the assessment.

\section{Hearing assessment}

This hearing assessment was made up of two stages. In the first, evaluations were carried out to establish whether the subjects met the inclusion 
criteria. In the second, an evaluation was carried out involving procedures related to the study's variables. In the first stage, an otoscopy examination, audiometric threshold testing from 0.25 to $8 \mathrm{kHz}$, impedanciometry, and a revision of the subject's medical history was performed. The second stage comprised an audiometric threshold testing at 3 and $6 \mathrm{kHz}$ and distortion product otoacoustic emissions between 2 and $10 \mathrm{kHz}$. An evaluation of exposure to dental and recreational noise was carried out using a questionnaire.

The audiometric assessment was carried out in a soundproof booth with an Interacoustics AC40 audiometer calibrated according to the ANSI S3.6 norm. The hearing thresholds were determined using a modified version of the procedure developed by Hughson-Westlake ${ }^{15}$. Then, distortion product otoacoustic emissions were measured using a Titan portable device by Interacoustics.

The Recreational Hearing Habits Questionnaire (CHAR in Spanish) $)^{14,16}$, the Noise Exposure Questionnaire (CER in Spanish) ${ }^{17}$ and a Hearing Health Survey were applied to quantify dental and recreational noise exposure. The CHAR questionnaire aimed to determine the hearing habits of teenagers and young people and the context of their exposure to recreational noise. The $\mathrm{CHAR}^{14,16}$ includes 14 closed-answer questions, with three to five answer alternatives. The maximum score per question is five, with the score increasing according to the noise level associated with each behavior and frequency. The questionnaire evaluates three sources of exposure: (1) Characteristics of personal music players, period, frequency, and context of use; (2) Attendance to concerts; and (3) Attendance to other noisy venues. The CHAR questionnaire has 14 questions in all, with a top score of five points for each one, giving a maximum of 70 points.

EI CER questionnaire ${ }^{17}$ is made up of 14 questions based on leisure activities, including the number of days each week the activity is carried out, the number of hours per day, an estimation of the noise level and the time in years of exposure to those activities. Since the CER questionnaire does not have normative values, the answers for each activity involving exposure to recreational noise were included separately in the statistical models (see below). Thus, they were used as covariates in the multivariate linear regressions models. The Hearing Health Survey was based on the Hearing Symptom Description Scale (HSD) ${ }^{18}$, and was made up of $22 \mathrm{yes/no}$ questions, multiple-choice questions, and an exclusive section for dentistry students explicitly created for this study. It aimed to evaluate the selfperception of symptoms such as temporary/permanent tinnitus, hearing loss, and pain after exposure to loud noises. These questions were treated as categorical data (yes/no) and included in the multivariate regressions models as covariates. Both the CHAR and the CER questionnaires have been validated in Chile.

\section{Notch definition}

The presence of a hearing notch was determined using the definition proposed by Coles et al. ${ }^{2}$. According to these authors, the presence of notch occurs when the (worst) audiometric threshold ( $\mathrm{dB}$ $\mathrm{HTL}$ ) at the 3,4 and/or $6 \mathrm{kHz}$ frequencies is less than $10 \mathrm{~dB}$ higher than at the 1,2 , and $8 \mathrm{kHz}$ frequencies ${ }^{12}$.

\section{Statistical analysis}

All analyses were conducted using STATA software version 14 [StataCorp LP, College Station, TX, USA], considering a $5 \%$ level for hypothesis significance testing. The quantitative variables were described using the mean and standard deviation (SD), or median and minimum ranges when applicable. In the case of categorical variables, absolute and relative frequencies were reported.

The Shapiro-Wilk test showed that the audiometric thresholds did not have a normal distribution. Accordingly, the non-parametric Mann Whitney test was used to compare thresholds between groups.

Based on Coles et al. ${ }^{12}$ definition, the notch prevalence was established at the 3, 4, and $6 \mathrm{kHz}$. Odds ratios with their respective 95\% confidence intervals $(95 \% \mathrm{Cl})$ were estimated through univariate logistic models and aimed to compare the notch prevalence between groups. To adjust the differences in notch prevalence, given the unequal distribution in other variables, such as students' age and gender, multivariate logistic regression models were constructed. Although there were more women in the total sample, this difference turned out to be uniform among dentistry students (exposed to occupational noise) and the control group. A second multivariate regression model included additional adjustments for recreational noise exposure, controlling this variable's confounding effect. Controlling the confounding effect using regression models is a widely used strategy ${ }^{19-22}$. Notch presence could be associated with recreational noise exposure instead dental noise. As previously mentioned, some 
studies identified a relationship between exposure to recreational noise and hearing damage ${ }^{13,14}$.

In the case of distortion product otoacoustic emissions, multivariate linear regression models were created. Since the outcome variable (otoacoustic emissions) did not have a normal distribution, standard errors were estimated using bootstrapping $(10,000$ replications). The $95 \% \mathrm{Cl}$ were obtained using the biascorrected and accelerated method ${ }^{23}$.

\section{RESULTS}

Forty-two students from the dentistry undergraduate program routinely exposed to occupational noise were evaluated. The control group was comprised of 78 students from other health-related undergraduate programs. The sample had more women $(74.2 \%)$ than men, and the average age was 22.0 years $(S D=1.9)$, with a borderline statistical difference between both groups $(p=0.05)$.

\section{Dental noise exposure}

All the students in the dentistry undergraduate program involved in this study were exposed to occupational dental noise. The average number of days per week of dentistry students' exposure was three $(S D=1$ day). The minimum exposure was one day a week, and the maximum was five.

\section{Recreational noise exposure}

In the CHAR questionnaire, it should be noted that $11.7 \%$ of the sample did not use portable musical players, while almost $50 \%$ indicated that they used less than two of these. In addition, almost $60 \%$ of the sample said they had used portable music players for more than six years. In the case of concert attendance, $68 \%$ of students indicated that they went to concerts. Of these, $28 \%$ indicated that they had been going to these for more than six years. Similar results for exposure to recreational noise were obtained in the CER questionnaire.

The control group's mean score in the questionnaire was 39.1 points ( $S D=12.6$, fluctuating between four and 58 points). In the group exposed to occupational noise, the mean score was 40.5 ( $S D=14.1$, fluctuating between five and 61 points). There were no significant differences between the scores of both groups $(z=$ -0.658; $p=0.51$ ) (Table 1), nor were there significant differences between these scores when these were adjusted for students' gender and age $(z=0.27 ; p=$ $0.789)$.

Table 1. Recreational Hearing Habits Questionnaire (CHAR in Spanish) scores obtained in a sample of dentistry undergraduate students and a control group $(\mathrm{N}=120)$

\begin{tabular}{cccccccc}
\hline & Mean & Median & 75 Percentile & 90 Percentile & $\begin{array}{c}\text { Standard } \\
\text { Deviation }\end{array}$ & Minimum & Maximum \\
\hline Control & 39.1 & 41.5 & 48.0 & 54.0 & 12.6 & 4 & 58 \\
Exposed & 40.5 & 42.5 & 50.0 & 56.0 & 14.1 & 5 & 61 \\
\hline Total & 39.6 & 42.0 & 50.0 & 54.0 & 13.1 & 4 & 61 \\
\hline
\end{tabular}

One of the CHAR questions allowed assessing hearing symptoms after noise exposure. Among the dentistry students, $28.6 \%$ had two symptoms, compared to $19.2 \%$ of the control group. The difference between them was $9.3 \%$, although this was not statistically significant. On the other hand, the number of years of exposure to recreational noise was significantly associated with a higher number of symptoms afterward (rho of Spearman $=0.61 ; p<0.001$ ).

\section{Audiometric thresholds}

Mann-Whitney's test showed no significant differences when comparing the group's thresholds exposed to dental noise and the control group (Table 2). There was no association between the audiometric thresholds and exposure to recreational noise. 
Table 2. Audiometric thresholds at 4,6 , and $8 \mathrm{kHz}$. obtained in a sample of dentistry undergraduate students and a control group $(\mathrm{N}=120)$

\begin{tabular}{|c|c|c|c|c|c|c|c|c|c|c|}
\hline Frequency & Ear & Group & Mean & Median & $\begin{array}{c}75 \\
\text { Percentile } \\
\end{array}$ & $\begin{array}{c}90 \\
\text { Percentile } \\
\end{array}$ & $\begin{array}{l}\text { Standard } \\
\text { Deviation }\end{array}$ & Minimum & Maximum & $p$-value ${ }^{a}$ \\
\hline \multirow{4}{*}{$4 \mathrm{kHz}$} & \multirow{2}{*}{ Right } & Control & 4.3 & 5.0 & 10 & 15 & 7.3 & -10 & 30 & \multirow{2}{*}{0.341} \\
\hline & & Exposed & 5 & 5.0 & 10 & 10 & 5.7 & -10 & 15 & \\
\hline & \multirow{2}{*}{ Left } & Control & 2.9 & 0.0 & 5 & 15 & 8.1 & -10 & 30 & \multirow{2}{*}{0.491} \\
\hline & & Exposed & 1.7 & 0.0 & 5 & 10 & 7.1 & -10 & 15 & \\
\hline \multirow{4}{*}{$6 \mathrm{kHz}$} & \multirow{2}{*}{ Right } & Control & 4.5 & 5.0 & 10 & 15 & 8.2 & -10 & 25 & \multirow{2}{*}{0.522} \\
\hline & & Exposed & 5.6 & 5.0 & 10 & 15 & 8.3 & -10 & 30 & \\
\hline & \multirow{2}{*}{ Left } & Control & 4.2 & 0.0 & 10 & 15 & 9.6 & -10 & 45 & \multirow{2}{*}{0.948} \\
\hline & & Exposed & 3.7 & 2.5 & 10 & 15 & 7.9 & -10 & 25 & \\
\hline \multirow{4}{*}{$8 \mathrm{kHz}$} & \multirow{2}{*}{ Right } & Control & 2.4 & 0.0 & 5 & 15 & 9.4 & -10 & 45 & \multirow{2}{*}{0.266} \\
\hline & & Exposed & 3.4 & 2.5 & 10 & 15 & 7.1 & -10 & 20 & \\
\hline & \multirow{2}{*}{ Left } & Control & 0.5 & 0.0 & 5 & 10 & 7.7 & -10 & 20 & \multirow{2}{*}{0.372} \\
\hline & & Exposed & 1.8 & 0.0 & 10 & 10 & 8.5 & -10 & 20 & \\
\hline
\end{tabular}

${ }^{a}$ Mann Whitney's non-parametric test was used to compare the thresholds between groups.

\section{Notch prevalence}

It should be noted that the greatest notch prevalence was obtained in the control group at $6 \mathrm{kHz}$ in the left ear (17.9\%; 95\% Cl 10.8-28.3). The lowest was in the exposed group at $4 \mathrm{kHz}$ in the left ear $(2.4 \% ; 95 \%$ Cl 0.3-16.4) (Table 3). Since there were distribution differences according to the groups' gender and age, with a higher number of women and a lower average age in the non-exposed group, multivariate logistic regressions models were used. In these multivariate models, the number of hours of dental noise exposure was not associated with the notch prevalence.

Table 3. Notch prevalence and odds ratios $(\mathrm{OR})$ at 3,4 , and $6 \mathrm{kHz}$ in the group exposed to occupational dental noise and the control group $(\mathrm{N}=120)$

\begin{tabular}{|c|c|c|c|c|c|c|}
\hline Frequency & Ear & Group & $\begin{array}{c}\text { Notch } \\
\text { prevalence (\%) }\end{array}$ & $\begin{array}{c}\text { Univariate OR } \\
(95 \% \mathrm{Cl})\end{array}$ & $\begin{array}{c}\text { Multivariate } \mathrm{OR}^{\mathrm{a}} \\
(95 \% \mathrm{CI})\end{array}$ & $\begin{array}{c}\text { Multivariate } \mathrm{OR}^{\mathrm{b}} \\
(95 \% \mathrm{CI})\end{array}$ \\
\hline \multirow{4}{*}{$3 \mathrm{kHz}$} & \multirow{2}{*}{ Right } & Control & 5.1 & 0.92 & 0.77 & 0.78 \\
\hline & & Exposed & 4.7 & $(0.16-5.27)$ & $(0.12-5.02)$ & $(0.12-5.16)$ \\
\hline & \multirow{2}{*}{ Left } & Control & 14.1 & 0.30 & 0.23 & 0.23 \\
\hline & & Exposed & 4.7 & $(0.06-1.44)$ & $(0.04-1.15)$ & $(0.04-1.20)$ \\
\hline \multirow{4}{*}{$4 \mathrm{kHz}$} & \multirow{2}{*}{ Right } & Control & 10.3 & 0.92 & 0.72 & 0.87 \\
\hline & & Exposed & 9.5 & $(0.26-3.26)$ & $(0.19-2.73)$ & $(0.22-3.38)$ \\
\hline & \multirow{2}{*}{ Left } & Control & 15.4 & 0.13 & 0.11 & 0.12 \\
\hline & & Exposed & 2.4 & $(0.02-1.07)$ & $(0.01-0.97)^{\star}$ & $(0.01-1.04)$ \\
\hline \multirow{4}{*}{$6 \mathrm{kHz}$} & \multirow{2}{*}{ Right } & Control & 8.9 & 1.4 & 1.56 & 1.84 \\
\hline & & Exposed & 11.9 & $(0.40-4.61)$ & $(0.44-5.48)$ & $(0.43-7.83)$ \\
\hline & \multirow{2}{*}{ Left } & Control & 17.9 & 0.62 & 0.49 & 0.50 \\
\hline & & Exposed & 11.9 & $(0.21-1.85)$ & $(0.15-1.59)$ & $(0.15-1.66)$ \\
\hline
\end{tabular}

${ }^{a}$ Adjusted by age and gender in a multivariate logistic model.

${ }^{\mathrm{b}}$ Adjusted by age, gender and recreational noise exposure in a multivariate logistic model.

$* p<0.05$. 
The odds of having a notch at $4 \mathrm{kHz}$ in the left ear was $88.7 \%$ lower among dental students $(\mathrm{OR}=0.11$; $95 \% \mathrm{Cl} 0.01-0.98)$. The result was similar at $3 \mathrm{kHz}$ in the same ear $(\mathrm{OR}=0.25 ; 95 \% \mathrm{Cl} 0.04-1.15)$, although the statistical difference was borderline. There were no differences between the exposed groups regarding the odds of having a notch in the rest frequencies.

The logistic regression models were adjusted for other covariates, given the possibility that the differences in thresholds might be explained by exposure to other noise sources. These variables were the recreational noise exposure at concerts, the number of years attending to concerts, use of ear protection, and the symptoms perceived afterward. In the multivariate regression model including these variables, the dental noise exposure was not significantly associated with a notch in either the left $(\mathrm{OR}=0.12 ; 95 \% \mathrm{Cl} 0.01-1.04)$ or the right ear $(\mathrm{OR}=0.87 ; 95 \% \mathrm{Cl} 0.22-3.38)$.

\section{Distortion product otoacoustic emissions}

There were no significant differences between the groups in all frequencies assessed in both ears. These analyses between groups in otoacoustic emissions were adjusted for age, gender, years of use of portable music players, and concert attendance (Table 4).

Table 4. Mean differences in the level of distortion product otoacoustic emissions between $3,210 \mathrm{~Hz}$ and $10,000 \mathrm{~Hz}$ a,b

\begin{tabular}{|c|c|c|c|c|c|}
\hline Ear & Frequency $(\mathrm{Hz})$ & $\begin{array}{l}\text { Mean difference }^{\mathrm{c}} \\
(95 \% \mathrm{Cl})\end{array}$ & Ear & Frequency $(\mathrm{Hz})$ & $\begin{array}{c}\text { Mean difference }^{\mathrm{c}} \\
(95 \% \mathrm{CI})\end{array}$ \\
\hline \multirow{26}{*}{ Left } & \multirow{2}{*}{3210} & 0.41 & & \multirow{2}{*}{3210} & 0.93 \\
\hline & & $(-2.84-3.66)$ & & & $(-3.12-4.40)$ \\
\hline & \multirow{2}{*}{3529} & -0.58 & & \multirow{2}{*}{3529} & 1.00 \\
\hline & & $(-4.35-3.18)$ & & & $(-2.77-5.51)$ \\
\hline & \multirow{2}{*}{3880} & 0.58 & & \multirow{2}{*}{3880} & 1.30 \\
\hline & & $(-3.79-4.95)$ & & & $(-2.16-4.77)$ \\
\hline & \multirow{2}{*}{4265} & 0.66 & & \multirow{2}{*}{4265} & 1.26 \\
\hline & & $(-4.07-5.39)$ & & & $(-2.93-5.72)$ \\
\hline & \multirow{2}{*}{4688} & 0.92 & & \multirow{2}{*}{4688} & 2.60 \\
\hline & & $(-3.14-4.98)$ & & & $(-0.53-6.59)$ \\
\hline & \multirow{2}{*}{5154} & 1.01 & & \multirow{2}{*}{5154} & 2.35 \\
\hline & & $(-3.38-5.41)$ & & & $(-1.59-6.27)$ \\
\hline & \multirow{2}{*}{5666} & -0.14 & Bioht & \multirow{2}{*}{5666} & 1.40 \\
\hline & & $(-3.68-3.41)$ & Right & & $(-2.78-5.04)$ \\
\hline & \multirow{2}{*}{6229} & 2.01 & & \multirow{2}{*}{6229} & 2.98 \\
\hline & & $(-2.02-6.04)$ & & & $(-1.14-7.12)$ \\
\hline & \multirow{2}{*}{6847} & 2.29 & & \multirow{2}{*}{6847} & 2.34 \\
\hline & & $(-1.81-6.38)$ & & & $(-1.54-6.66)$ \\
\hline & \multirow{2}{*}{7527} & 1.35 & & \multirow{2}{*}{7527} & 2.35 \\
\hline & & $(-3.13-5.84)$ & & & $(-1.40-7.44)$ \\
\hline & \multirow{2}{*}{8257} & 0.45 & & \multirow{2}{*}{8257} & 1.95 \\
\hline & & $(-4.70-5.60)$ & & & $(-2.05-5.80)$ \\
\hline & \multirow{2}{*}{9096} & 0.81 & & \multirow{2}{*}{9096} & 2.45 \\
\hline & & $(-5.61-7.24)$ & & & $(-2.51-7.08)$ \\
\hline & \multirow{2}{*}{10000} & 1.47 & & \multirow{2}{*}{10000} & 5.21 \\
\hline & & $(-5.27-8.22)$ & & & $(-1.31-11.38)$ \\
\hline
\end{tabular}

a Mean was estimated with respective confidence intervals at $95 \%$ level (95 Cl\%).

${ }^{\mathrm{b}}$ Multivariate linear models were used with the standard error estimated using bootstrapping (10,000 reps).

${ }^{\mathrm{c}}$ Mean differences adjusted by age, gender and exposure to recreational noise in multivariate linear models. 


\section{DISCUSSION}

The study aimed to determine the auditory effects of noise exposure from recreational and occupational sources among dentistry students. The total sample comprised 120 students, of whom 42 were exposed to dental noise, and 78 were from other health-related undergraduate programs. Although there was a sample size ratio of 1:1.7 between groups, the control group usually has a large sample size than the control group, improving the statistical power of the analyses. The differences in audiometric thresholds and notch prevalence between those exposed or not to dental noise were assessed. The comparisons were initially adjusted for age and gender into the regression models. They also were adjusted for years of concert attendance, ear protection at concerts, and exposure symptoms afterward.

As far as hearing thresholds are concerned, there were no differences between groups at any hearing frequencies, although there was a certain tendency among dentistry students to have better thresholds in the right ear compared to the control group. These results are similar to a previous study ${ }^{24}$ where the differences in hearing thresholds were not significant but, when establishing the notch prevalence, there were significant differences with respect to a control group at 4 and $6 \mathrm{kHz}$. In this current study, students not exposed to occupational noise had a greater prevalence of notch at $4 \mathrm{kHz}$ in the left ear when the model was adjusted for age and gender.

These contradictory results are related to students' exposure to recreational noise at concerts. In the multivariate model adjusted for the years of concert attendance, ear protectors use at these events, and for hearing-related symptoms afterward, the difference in the thresholds was not significant. This result means that the differences in notch prevalence at $4 \mathrm{kHz}$ could be explained by recreational noise exposure and not by occupational dental noise exposure. By adjusting the regression models for concert attendance (in years) and the subjects' age, the multivariate model performed may be capturing exposure over time, which is difficult to measure in this type of cross-sectional study.

Exposure to recreational noise in years is significantly related to a higher number of hearing-related symptoms reported afterward. Also, there were differences in the symptomatology perceived, according to whether the subject was exposed to occupational dental noise. A total of $28.6 \%$ of dentistry students had two symptoms after noise exposure, compared to
$19.2 \%$ in the control group. Theoretical models such as the Health Belief Model (HBM) could explain the relationship between hearing-related symptoms, type of exposure, and hearing thresholds. In this theoretical model, the symptoms act as an alert, generating a change in risk perception and behavior ${ }^{25}$. It would be hypothesized that by being exposed to occupational noise and having a higher number of symptoms, dentistry students change their exposure to recreational noise, leading to better thresholds. This hypothesis could not be tested in this current cross-sectional design; therefore, it should be considered in future studies.

As reported by recent studies, the lower noise level from dental instruments could explain the non-significant differences between groups in thresholds observed in this current study. In 2008, Brusis et al. ${ }^{26}$ analyzed the noise produced by the instruments used in dental practices, observing that the average noise level was between 70-77 dB. In 2011, Lourenço et al. ${ }^{27}$ concluded that the noise generated by dental drills was below the limit causing hearing damage. In 2015, Castro-Espinosa et al. ${ }^{28}$ observed that the average noise produced by NSK dental instruments, the most used brand by dentistry students in this study, was 79.3 $\mathrm{dB}$, which does not exceed the limit of $85 \mathrm{~dB}$.

\section{Study limitations}

One of the limitations was not considering the year attended by the students in the undergraduate program. This variable would have allowed evaluation of a dose-response relationship between dental noise exposure and the hearing threshold decreasing. Weatherton et al. ${ }^{29}$ evaluated dentistry professors and students, with worse thresholds seen at 4 and $6 \mathrm{kHz}$, and proposed that thresholds changing is gradual and begins at these frequencies.

Another possible limitation is that students answered the questionnaires based on their current exposure to recreational noise and not according to their exposure history. Noise exposure over time is not captured in the cross-sectional questionnaires. Nevertheless, two of the CHAR's questions evaluated the use (in years) of personal music players and concert attendance (accumulate noise doses). Together with students' age, these allowed us to recreate exposure over time in the statistical models.

Although the confounding effect was controlled through statistical models, there might have been some residual confounding as well, in other words, 
an incomplete adjustment of the covariates $^{30}$. Another way of controlling the effect of confounder variables is through exclusion. However, given that recreational noise exposure is common among young people ${ }^{31}$, it would have been difficult to recruit a group that had not been exposed to this kind of noise. Also, the generalizability of results would have been limited since it is difficult to find young people who have not been exposed to any recreational noise at some point in their lives.

\section{Projections}

Given the results obtained, it is essential to draw up programs to prevent and raise awareness among university students' exposure to recreational noise. Paradoxically, students from undergraduate healthcare programs, including those studying speech-language therapy, have altered hearing thresholds, despite being provided with information about the damage caused by recreational noise exposure. Therefore, it is not enough to provide theoretical information about the effects of exposure to recreational noise for changing students' behavior.

Another projection would be to estimate the noise present in these students' dental laboratories as compared with that of other university laboratories. Previous studies in New Zealand have reported significant differences between university undergraduate clinics ${ }^{7}$. Future studies could also evaluate differences according to the clinical procedure performed by the student, differentiating between those that show a peak in high frequencies and those that do not.

\section{CONCLUSIONS}

In short, there were no significant differences in the audiometric thresholds of the groups studied. The tendency towards better thresholds in the group exposed to occupational dental noise stood out compared to the non-exposed group. The control group had a higher prevalence of notch at $4 \mathrm{kHz}$ when the statistical model was adjusted for gender and age. However, this prevalence difference was not significant when the statistical model was adjusted for the number of years of concert attendance, ear protection use at these events, and exposure symptoms afterwards.

\section{ACKNOWLEDGEMENTS}

The authors would like to thank the Dentistry, Nutrition and Dietetics, Physiotherapy, and
Speech-Language Therapy undergraduate students for their willingness to participate. They would also like to thank Rodrigo Troncoso and Anthony Marcotti for collaborations in the sample's assessment.

\section{REFERENCES}

1. Willershausen B, Callaway A, Wolf TG, Ehlers V, Scholz $L$, Wolf $D$ et al. Hearing assessment in dental practitioners and other academic professionals from an urban setting. Head Face Med. 2014;18(10):1.

2. Seidman $M$, Standring R. Noise and quality of life. Int J Environ Res Public Health. 2010;7(10):3730-8.

3. Instituto de Salud Pública de Chile. "Protocolo para la Medición del Ruido Impulsivo en los Lugares de Trabajo". Santiago de Chile: Ministerio de Salud de Chile; 2012.

4. McBride DI, Williams S. Audiometric notch as a sign of noise induced hearing loss. Occup Environ Med. 2001;58(1):46-51.

5. Liberman MC, Epstein MJ, Cleveland SS, Wang $\mathrm{H}$, Maison SF. Toward a differential diagnosis of hidden hearing loss in humans. PLoS One. 2016;11(9):e0162726.

6. Qsaibati ML, Ibrahim O. Noise levels of dental equipment used in dental college of Damascus University. Dent Res J (Isfahan). 2014;11(6):624-30.

7. Al-Dujaili M, Thompson W, Meldrum R, Al-Ani A. noise levels in dental school clinics. $\mathrm{N} Z$ Dent $\mathrm{J}$. 2014;110(3):105-8.

8. Sampaio Fernandes J, Carvalho A, Gallas M, Vaz P, Matos P. Noise levels in dental schools. Eur J Dent Educ. 2006;10(1):32-7.

9. Gijbels F, Jacobs R, Princen K, Nackaerts O, Debruyne F. Potential occupational health problems for dentists in Flanders, Belgium. Clin Oral Investig. 2005;10(1):8-16.

10. Bali N, Acharya S, Anup N. An assessment of the effect of sound produced in a dental clinic on the hearing of dentists. Oral Health Prev Dent. 2007;5(3):187-91.

11. Wilson C, Vaidyanathan $T$, Cinotti W, Cohen S, Wang $S$. Hearing-damage risk and communication interference in dental practice. J Dent Res. 1990;69(2):489-93.

12. Coles R, Lutman M, Buffin J. Guidelines on the diagnosis of noise-induced hearing loss for medicolegal purposes. Clin Otolaryngol Allied Sci. 2000;25(4):264-73.

13. Kraaijenga V, Ramakers G, Grolman W. The effect of earplugs in preventing hearing loss from 
recreational noise exposure. JAMA Otolaryngol Head Neck Surg. 2016;142(4):389.

14. Fuentes López EA, Morales FC. Construction and validation of questionnaire to assess recreational noise exposure in university students. Noise Health. 2014;16(72):292-8.

15. International Organization of Standardization. Acoustics. Audiometric test methods-Part 1: Basic pure tone air and bone conduction threshold audiometry. Geneva: ISO.1989.

16. Fuentes E, Cardemil F. Validación de criterio y constructo para la creación de un cuestionario de exposición a ruido. Rev. Otorrinolaringol. Cir. Cabeza Cuello. 2014;74(1):23-8.

17. Zenker F, Altahona MP, Barajas JJ. La exposición a ruido por actividades de ocio en adolescentes. Rev Logop Fon Adiol. 2001;21(4):173-80.

18. Olsen-Widén SE, Erlandsson SI. The influence of socio-economic status on adolescent attitude to social noise and hearing protection. Noise Health. 2004;7(25):59-70.

19. Greenland S, Pearce N. Statistical foundations for model-based adjustments. Annu Rev Public Health. 2015;36(1):89-108.

20. Szklo M, Nieto FJ. Epidemiology: beyond the basics. 4. Sudbury: Jones and Bartlett Publishers; 2014.

21. Rothman K, Greenland S, Lash TL. Modern epidemiology. 3. London: Lippincott Williams \& Wilkins; 2008.

22. Bonita R, Beagelhole R, Kjellström T. Basic epidemiology. 2. Geneva: WHO; 2006.

23. Carpenter J, Bithell J. Bootstrap confidence intervals: when, which, what? A practical guide for medical statisticians. Stat Med. 2000;19(9):1141-64.

24. Fuentes E, Rubio C, Cardemil F. Pérdida auditiva inducida por ruido en estudiantes de la carrera de odontología. Rev. Otorrinolaringol. Cir. Cabeza Cuello. 2013;73(3):249-56.

25. Soto Mas F, Lacoste Marín J, Papenfuss R, Gutiérrez León A. El modelo de creencias de salud. Un enfoque teórico para la prevención del sida. Rev. Esp. Salud Publica. 1997;71(4):335-41.

26. Brusis $T$, Hilger R, Niggeloh R, Huedepohl J, Thiesen KW. Are professional dental health care workers (Dentist, dental technicians, assistants) in danger of noise induced hearing loss? LaryngoRhino-Otol. 2008;87(5):335-40.
27. Lourenço EA, Berto JMR, Duarte SB, Greco JPM. Can noise in dental clinic produce hearing loss? Int. Arch. Otorhinolaryngol. 2011;15(1):84-8.

28. Castro-Espinosa J, Ortiz-Julio S, Tamayo-Cabeza G, González-Martínez F. Niveles de ruido en clínicas odontológicas de la Universidad de Cartagena. Revista Colombiana de investigación en Odontología. 2015;6(17):69-76.

29. Weatherton MA, Melton RE, Burns WW. The effects of dental drill noise on the hearing of dentists. $J$ Tenn State Dent Assoc. 1972;52(4):305-8.

30. Becher $\mathrm{H}$. The concept of residual confounding in regression models and some applications. Stat Med. 1992;11(13):1747-58.

31. Hearing loss due to recreational exposure to loud sounds: a review. Geneva: World Health Organization; 2015. Último acceso 19 Julio 2020. Disponible en: http://apps.who.int/iris/bitst ream/10665/154589/1/9789241508513_eng. pdf?ua $=1 \&$ ua $=1 /$ 